\title{
Preliminary analysis of the dynamic behavior of two strategic buildings subjected to the 2016 Central Italy earthquake
}

\author{
C. Iacovino \\ Center of Integrated Geomorphology for the Mediterranean Area, Potenza, Italy, \\ School of Engineering, University of Basilicata, Potenza, Italy \\ R. Ditommaso \& F.C. Ponzo \\ School of Engineering, University of Basilicata, Potenza, Italy \\ M.P. Limongelli \\ Department of Architecture, Built Environment and Construction Engineering, Milan, Italy
}

\begin{abstract}
This paper reports the preliminary results obtained from a campaign of experimental measurements carried out on two strategic structures located in Central Italy and affected by the seismic sequence started on August 24, 2016. The epicentre was located among the municipalities of Accumoli (province of Rieti), Amatrice (province of Rieti) and Arquata del Tronto (province of Ascoli Piceno). About 51 seismic events have been recorded from August 24, 2016 to February 03, 2017. The dynamic characterization of a hospital in Spoleto and of a school in Norcia retrofitted with dissipative bracing devices, were carried out to detect the stiffness variation, assumed as damage indicator, during the seismic sequence. Data was provided by the Seismic Observatory of Structures (OSS), a network of permanent seismic monitoring systems installed on public buildings, bridges and dams and managed by the Italian Department of Civil Protection (DPC). Modal parameters have been identified from the accelerometric responses recorded at several floors of the buildings.
\end{abstract}

\section{INTRODUCTION}

On August 24, 2016 at 03.36 a.m. (Italian time), a Mw 6.0 earthquake struck an extensive portion of Central Italy. The epicenter was located among the municipalities of Accumoli (province of Rieti), Amatrice (province of Rieti) and Arquata del Tronto (province of Ascoli Piceno). In the following months several shakings occurred in the region and, on October 30, 2016 at 06:40:17 UTC (07:40:17, Italian time), the Italian strongest seismic event - after the 1980 Irpinia earthquake (MW 6.9) - struck again the Central Italy. The local magnitude evaluated by the INGV was equal to 6.1 ML and the moment magnitude was 6.5 MW. The earthquake affected the provinces of Perugia, Rieti and Macerata and was strongly felt in Central Italy; the epicenter was located at $5 \mathrm{~km}$ from Norcia, $7 \mathrm{~km}$ from Castelsantangelo sul Nera and Preci, and $10 \mathrm{~km}$ from Visso.

This was the strongest event of the sequence started with the earthquake of August 24 (MW 6.0) and was followed by a quake of magnitude MW 5.9 of October 26, 2016 (INGV 2016).

This seismic sequence occurred in a territory already affected by relevant earthquakes in the past.
Some of these historical earthquakes occurred in sequences but, none of them, comparable with that recorded in 2016.

In the Amatrice area, the most affected by the August 24 earthquake, a cluster of four strong earthquakes occurred in: 1627 (Accumoli, MW 5.3); 1639 (Amatrice, MW 6.2); 1646 (Monti della Laga, MW 5.9) and 1672 (Amatrice, MW 5.3).

After the main shock of August 24, 2016 several technical and scientific activities started with the aim to carry out preliminary evaluations on the characteristics of the seismic sequence. Data recorded in situ were provided by the Italian Department of Civil Protection (DPC) engaged in several emergency and rescue management actions. One of the most important activities of DPC is the seismic monitoring of civil structures of public property through the Seismic Observatory of Structures (OSS) Project, a network of permanent seismic monitoring systems installed on public buildings, bridges and dams (Dolce et al. 2017).

In this paper are reported some preliminary analyses carried out using the responses recorded by the OSS on two strategic buildings, a hospital in Spoleto and a school in Norcia, during the seismic sequence occurred in 2016. 


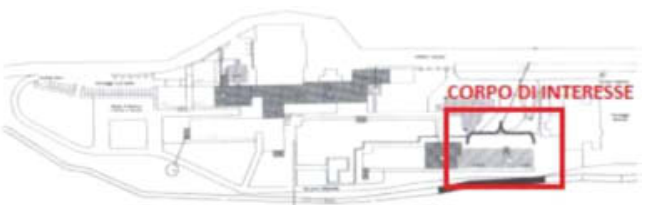

(a)

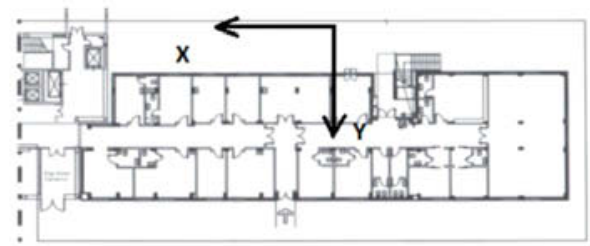

(b)

Figure 1. (a) Plan of the building; (b) monitored block.
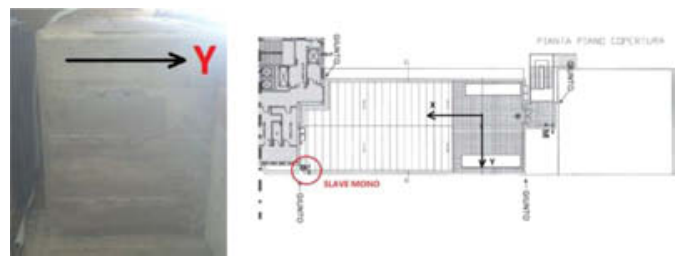

Figure 2. Poseidon "Slave Mono".

\section{CASE STUDY 1: HOSPITAL IN SPOLETO}

On the hospital in Spoleto, monitored by the OSS, around 51 seismic events were recorded in the period from August 24, 2016 to February 03, 2017.

Figure 6.2 shows the plan of the structure and of the monitored block (in the red frame) with the of the axis directions. The hospital is a multistory building with $16.95 \mathrm{~m}$ height.

The monitoring system consists of the following elements:

- three Poseidon recorders: a mono-axial $(+/-1.0 \mathrm{~g})$, a biaxial $(+/-1.0 \mathrm{~g})$ and a triaxial accelerometer $(+/-0.5 \mathrm{~g})$

- one router for remote communication with the server Rome;

- one repeater unit to allow communications among recorders.

In Figure 2 to Figure 4 are shown the sensors position and the measurements direction of the three different Poseidon recorders installed on the monitored structure. Poseidon "Master Biax", a biaxial accelerometer, and Poseidon "Slave Mono", a mono-axial accelerometer both at the top floor of the building. The triaxial Poseison "Slave Triax" was installed at the bottom floor.
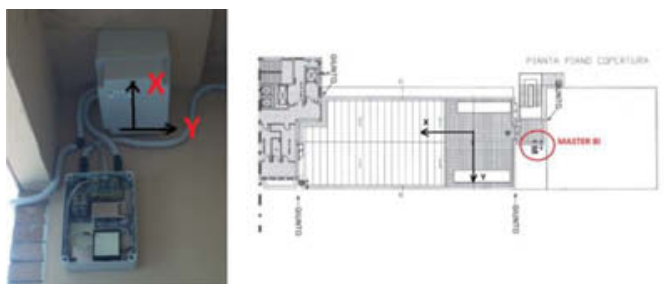

Figure 3. Poseidon "Master Biax".
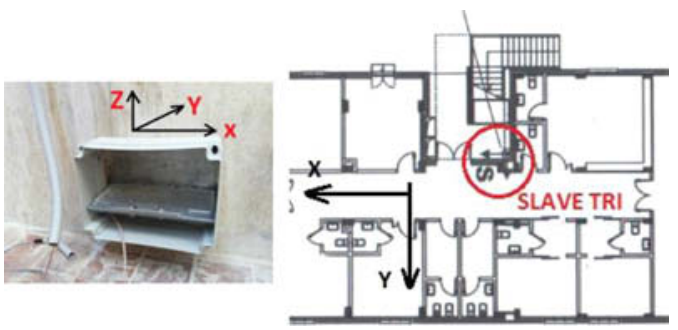

Figure 4. Poseidon "Slave Triax".
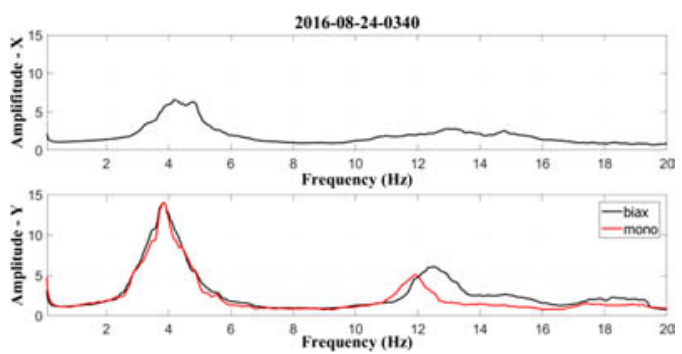

Figure 5. Transfer Functions evaluated from data recorded on August 24, 2016 at 03.40 a.m.

\subsection{Preliminary results}

In this paragraph are shown the results obtained by analyzing the different seismic events recorded during the considered period. In order to identify the dynamic characteristics of the test building (Pierdicca et al. 2019), the Transfer Functions have been calculated for all the recorded events along $\mathrm{X}$ and $\mathrm{Y}$ directions.

Figure 5 trough Figure 7 report the Transfer Functions computed using the responses recordes by the 3 accelerometers placed at the top story of the building: 2 in the Y direction (mono and biax) and one in $\mathrm{X}$ direction. All figures show that two modes are excited in $\mathrm{X}$ and $\mathrm{Y}$ direction and a gradual reduction of the first modal frequency occurs in the $\mathrm{Y}$ direction from August 24 to October 30 whereas the variation of the first modal frequency in the $\mathrm{X}$ direction appears much more limited.

Figure 8 shows the fundamental frequency distribution related to $\mathrm{X}$ and $\mathrm{Y}$ directions evaluated during the seismic events. Table 1 summarizes the values of median, percentile (25th) and percentile (75th) of the two different distributions, used to evaluate the data 

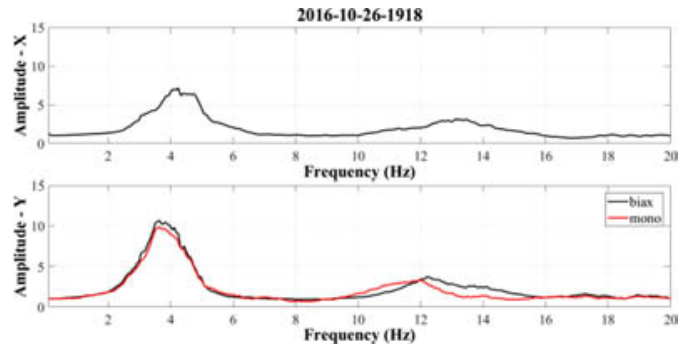

Figure 6. Transfer Functions evaluated from data recorded on October 26, 2016 at 19.18 p.m.
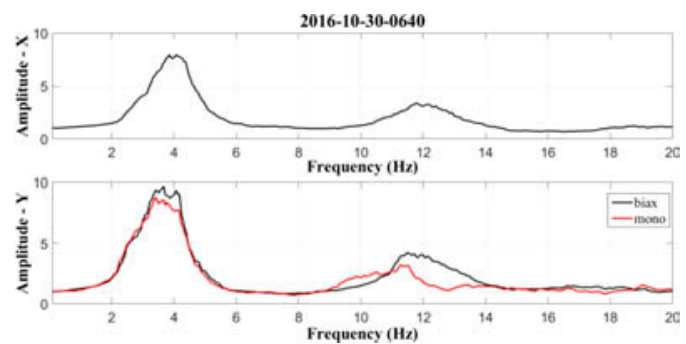

Figure 7. Transfer Functions evaluated from data recorded on October 30, 2016 at 06.40 a.m.
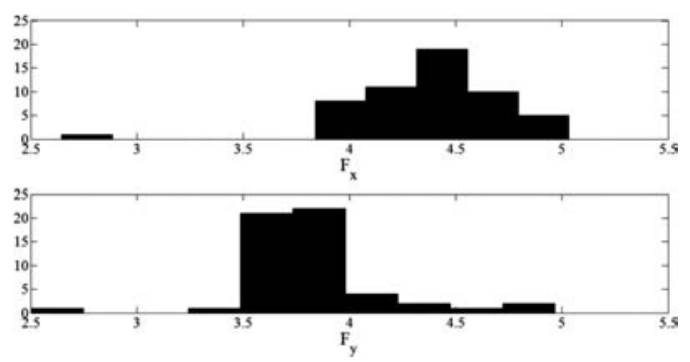

Figure 8. Relative frequency histograms.

Table 1. Values of median, percentile (25th) and percentile (75th).

\begin{tabular}{llll}
\hline & median & $\begin{array}{l}\text { Percentile } \\
(25 \text { th })\end{array}$ & $\begin{array}{l}\text { Percentile } \\
(75 \text { th })\end{array}$ \\
\hline Dir. X & 4.468 & 4.184 & 4.574 \\
Dir. Y & 3.777 & 3.673 & 3.902 \\
\hline
\end{tabular}

dispersion providing an estimate of the uncertainty of median values.

Analyses of the recorded responses have been performed to detect possible damages occurred on the monitored building during the seismic sequence. For this case study, due to the limited number of sensors, the recorded data were not available at each story of the monitored building. Therefore, it was not possible to identify the mode shapes of the structure (Iacovino et al. 2018, Ditommaso et al. 2015).

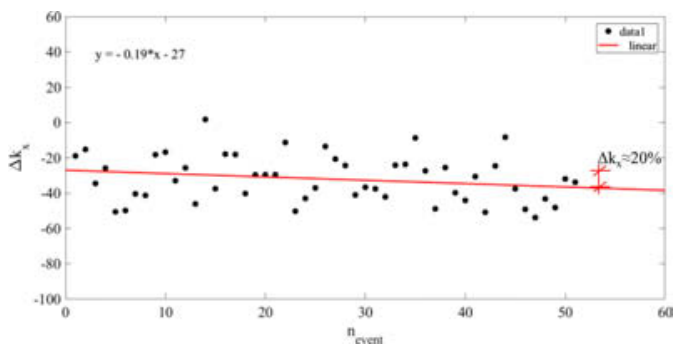

Figure 9. Stiffness Variation along X direction.

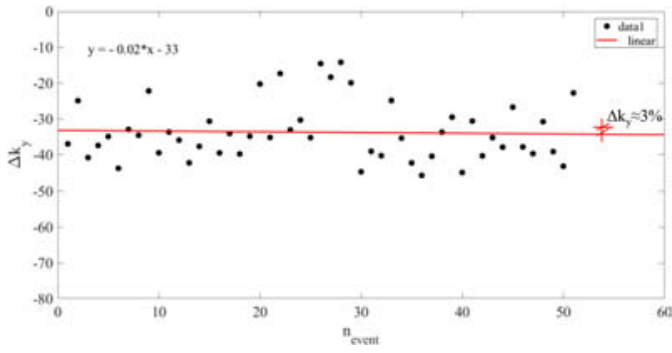

Figure 10. Stiffness Variation along Y direction.

The stiffness variation, computed as a function of the median frequency variation - between the final and the initial value, see eq.2, has been used as damage indicator.

$T=2 \pi \sqrt{\frac{k}{m}} \rightarrow k=\frac{4 \pi^{2}}{T^{2}} m$

$\Delta k=\frac{k_{f}-k_{i}}{k_{i}} \rightarrow \Delta k=\frac{f_{f}^{2}-f_{i}^{2}}{f_{i}^{2}}$

Figure 9 and Figure 10 show the stiffness variation evaluated considering all the seismic events recorded during the seismic sequence from August 24, 2016 to February 03, 2017. Particularly, on the $\mathrm{x}$-axis is reported the progressive number of each seismic events whereas on the vertical axis the stiffness variation along $\mathrm{X}$ and $\mathrm{Y}$ direction respectively is shown.

The stiffness variation evaluated over time is of about $20 \%$ of the initial $\left(\mathrm{k}_{\mathrm{i}}\right)$ value along the $\mathrm{X}$ direction and of about $3 \%$ along $\mathrm{Y}$ direction.

\section{CASE STUDY 2: SCHOOL IN NORCIA}

The second strategic building considered herein is secondary school located in Norcia (Figure 11). This reinforced concrete building was designed in the early 60 s with a frame structure composed of beams and pillars with rectangular section. The masonry infill is made of perforated bricks blocks. A technical joint separates the central body from the wings of the building. 

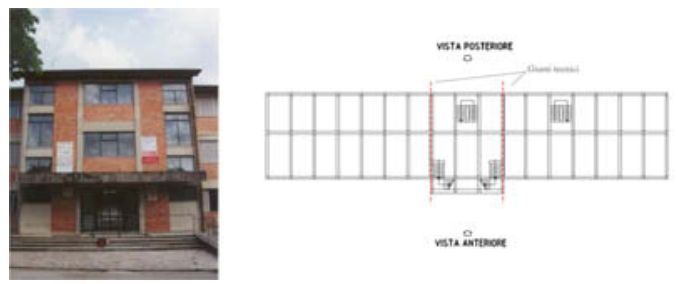

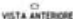

Figure 11. Secondary school of Norcia.

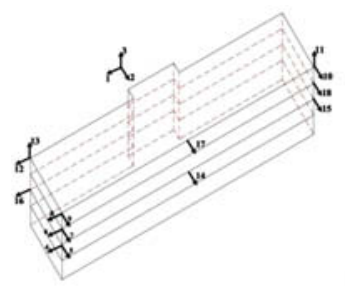

a)

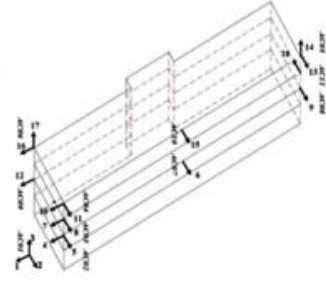

b)
Figure 12. a) Sensor position until 2010 and b) after 2010.

A steel truss elevator shaft located outside the reinforced concrete building is connected to its central block.

On June, 2000 the dynamic identification of the structure was conducted by the National Seismic Service by indirect impulsive excitation, i.e. using a concrete block of mass between 1000 and $2500 \mathrm{~kg}$ dropped on the ground from a height of $1-2 \mathrm{~m}$. The position of the sensors during these tests is shown in Figure 12.

Free vibrations induced by the drop of the mass were used to identify the values of the first three modal frequencies. The mean of the frequency values retrieved from the responses recorded at the instrumented locations were $3.64 \mathrm{~Hz}, 4.88 \mathrm{~Hz}$, and $6.00 \mathrm{~Hz}$ with standard deviations around $0.03,0.05$ and 0.18 for the three modes.

In 2005, a first intervention of seismic retrofit was carried out installing dissipative braces at the basement floor. The intervention was completed in 2010 by inserting a dissipative bracing system also at the upper floors in the two main directions of the building (Figure 13). These are hysteretic axial braces with unstable instability (according to NTC 2018) in which the dissipation of energy takes place due to the yielding of the material. They consist of an external steel tube and an internal steel core separated by a concrete filling in order to prevent the transmission of shear stresses between the two components.

\subsection{Available recorded events (2002-2017)}

Between July 2002 and June 2017, the monitoring system installed on the building recorded a sequence of seismic events (Dolce et al. 2017). Table 2 shows in the first two columns the values of peak ground accelerations in the longitudinal (1) and transverse (10) directions for each event. The other two columns a)

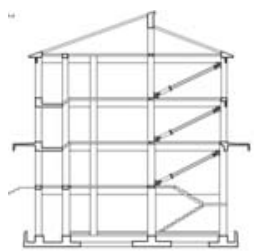

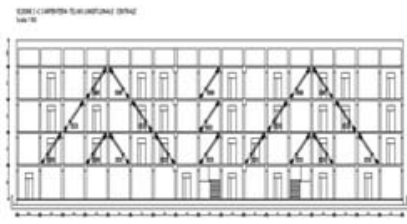

b)
Figure 13. a) Position of dissipative braces in a transversal frame and b) in a longitudinal frame.

Table 2. PGA and fundamental frequencies for events recorded in the period July 2002-June 2017.

\begin{tabular}{|c|c|c|c|c|}
\hline Event & $\begin{array}{l}\text { PGA_1 } \\
{[\mathrm{g}]}\end{array}$ & $\begin{array}{l}\text { PGA_2 } \\
{[\mathrm{g}]}\end{array}$ & $\begin{array}{l}\mathrm{f} \_1 \\
{[\mathrm{~Hz}]}\end{array}$ & $\begin{array}{l}\text { f_2 } \\
{[\mathrm{Hz}]}\end{array}$ \\
\hline 2002-07-07 & 0.075 & 0.064 & 3.03 & 4.39 \\
\hline $2008-02-15^{*}$ & 0.016 & 0.014 & 3.03 & 4.39 \\
\hline 2012-03-15 & 0.013 & 0.013 & 3.07 & 4.00 \\
\hline $2013-11-30$ & 0.005 & 0.008 & 4.20 & 4.54 \\
\hline $2015-07-25$ & 0.002 & 0.002 & 4.34 & 4.59 \\
\hline $2016-08-24^{(a)}$ & 0.287 & 0.506 & 3.10 & 3.10 \\
\hline $2016-08-24^{(b)}$ & 0.175 & 0.226 & 2.68 & 3.13 \\
\hline $2016-08-24^{(\mathrm{c})}$ & 0.068 & 0.067 & 2.60 & 3.22 \\
\hline 2016-09-03 & 0.086 & 0.082 & 2.78 & 3.12 \\
\hline $2016-10-26^{(a)}$ & 0.240 & 0.331 & 2.34 & 2.88 \\
\hline $2016-10-26^{(b)}$ & 0.495 & 0.482 & 2.15 & 2.92 \\
\hline $2016-10-30^{(a)}$ & 0.550 & 0.546 & 2.00 & 2.34 \\
\hline $2016-10-30^{(b)}$ & 0.061 & 0.057 & 1.90 & 3.03 \\
\hline 2016-11-03 & 0.044 & 0.051 & 2.24 & 3.07 \\
\hline $2017-01-18^{(a)}$ & 0.056 & 0.070 & 1.85 & 3.22 \\
\hline $2017-01-18^{(b)}$ & 0.039 & 0.038 & 2.00 & 2.98 \\
\hline $2017-01-18^{(\mathrm{c})}$ & 0.023 & 0.027 & 2.05 & 2.98 \\
\hline $2017-01-18^{(\mathrm{d})}$ & 0.041 & 0.027 & 2.00 & 2.98 \\
\hline $2017-02-03$ & 0.004 & 0.004 & 2.78 & 3.85 \\
\hline 2017-04-11 & 0.001 & 0.001 & 3.12 & 3.90 \\
\hline $2017-06-30$ & 0.004 & 0.005 & 2.92 & 3.90 \\
\hline
\end{tabular}

report the values of the fundamental frequencies $f \_1$ and $f \_2$ identified in the two directions. Modal frequencies retrieved from responses recorded at different locations do not exhibit sensible variations. In the following reference is made to the values identified from the sensors in the corner of the second story of the building.

These values have also been reported in Figure 14 to better highlight the evolution of the frequencies. The values of the frequencies have been identified with the peak-peaking method starting from the transfer functions (FRF) with respect to the base excitation.

\subsection{Analyses of recorded responses}

This section reports the main results obtained from the analysis of the responses recorded in two different configurations: pre and post- retrofit intervention. The modal parameters of the structure (fundamental frequency, mode shape, equivalent viscous damping factor) where identified using the transfer functions 


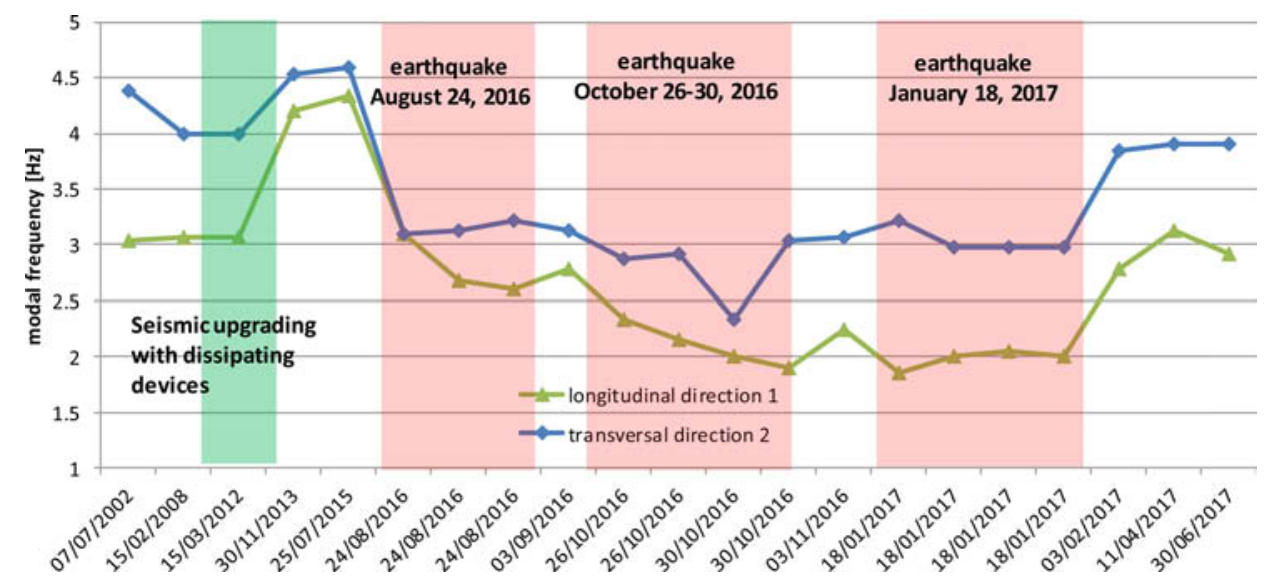

Figure 14. Evolution over time of modal frequencies in the longitudinal and transverse directions.

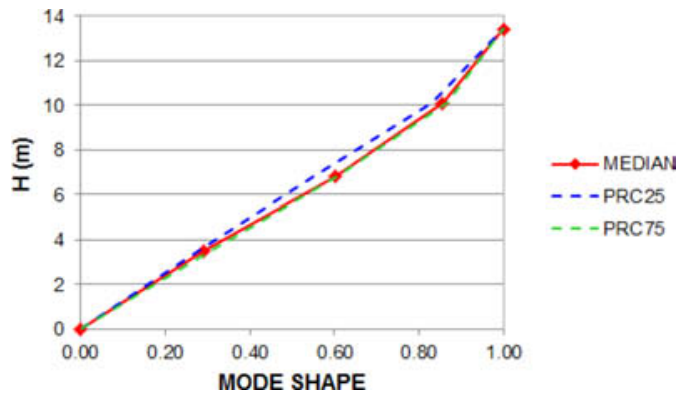

Figure 15. Trends of median mode shape, percentile (25th) and percentile (75th) for the strong motion phase.

of the recorded accelerations with respect to the base excitation (Maia et al. 2003, Sampaio et al. 1999).

As shown in Figure 14, frequency values increase between the events of 2008 and 2012 in both directions due to the retrofit intervention performed in 2010 . After the earthquake of August 24, 2016 there is a clear reduction of the frequencies in both directions 1 and 2 . The next event (October 2016) seems to have produced further reductions in the longitudinal direction (1) but not in the transversal one. The event of January 2018, with PGA one order of magnitude lower with respect to the previous events, did not produce sensible changes of frequencies in the two directions. The increase of frequencies during the last three events, recorded after February 2017, probably depends on their slow severity, with PGA ranging between $0.001 \mathrm{~g}$ and $0.004 \mathrm{~g}$ (see Table 2).

In order to evaluate possible variations in the dynamic behavior of the structure following the seismic events the modal shapes have been assessed from the recorded accelerations at each floor of the building. The event of November, 2013 together with the main earthquakes of August 24, 2016 and October 30, 2016 have been considered. Figure 15 and Figure 16 show the trend of the median mode shape calculated for both the strong motion (a time instant during the main shock) and the weak motion phases (a time instant at

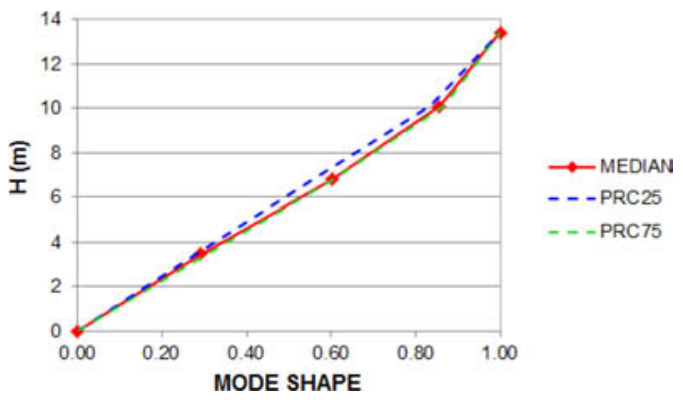

Figure 16. Trends of median mode shape, percentile (25th) and percentile (75th) for the weak motion phase.

the beginning of the record). The 25 th and the 75 th percentiles have been calculated to provide an estimation of the uncertainty of the mode shape.

The values of the equivalent viscous damping factor were calculated using the bandwidth method (Chopra 2007, Thomson 1993) for the seismic events of November, 2013, August 24, 2016 and October 30,2016 . By assuming that the damping ratio $\xi$ is small and that the frequency of maximum amplitude is approximately equal to the undamped natural frequency $\omega$, the classical result relating the damping ratio to the half-power bandwidth can be rewritten as:

$\xi=\frac{\omega_{2}-\omega_{1}}{2 \omega}$

where $\omega_{2}$ and $\omega_{1}$ are half-power frequencies. The classical result is valid for damping ratio less than 0.1 . On the contrary, the formula valid for systems with a higher equivalent viscous damping factor:

$\xi_{n l}=\frac{\omega_{2}^{2}-\omega_{1}^{2}}{2 \omega^{2}}$

Table 3 summarizes the values of the equivalent viscous damping factor for the analyzed seismic events. 
Table 3. Equivalent viscous damping factors.

\begin{tabular}{|c|c|c|c|c|}
\hline \multirow[b]{2}{*}{ Event } & \multicolumn{2}{|c|}{ Strong motion } & \multicolumn{2}{|c|}{ Weak motion } \\
\hline & $\xi$ & $\xi \mathrm{nl}$ & $\xi$ & $\xi \mathrm{nl}$ \\
\hline $30 / 11 / 2013$ & $7 \%$ & $14 \%$ & $6 \%$ & $12 \%$ \\
\hline $24 / 08 / 2016$ & $10 \%$ & $21 \%$ & $4 \%$ & $8 \%$ \\
\hline $30 / 10 / 2016$ & $7 \%$ & $15 \%$ & $4 \%$ & $8 \%$ \\
\hline
\end{tabular}

\section{CONCLUSIONS}

This work reports the results obtained from an experimental campaign carried out on two strategic structures located in Central Italy. The dynamic behavior of the hospital of Spoleto and of a school in Norcia, retrofitted with dissipative bracing devices, has been analyzed to evaluate possible damages occurred after the seismic sequence started on August 24, 2016. The preliminary results show that there are not significant structural nonlinearities following the sequence of earthquakes that excited the Spoleto Hospital. A decreasing trend of the stiffness values over time has been detected but further analyses are needed to detect possible damages. Analyzing data recorded by the monitoring system installed on the school of Norcia it can be noted a time evolution of the fundamental frequency consistent with an increase of stiffness due to the retrofit intervention. In fact, in both directions an increase in the fundamental frequencies between the earthquakes of 2008 and 2013 was detected. Following the earthquake of 24 August 2016 and October 2016, a reduction in the frequencies in both directions is observed. After the August seismic event, the frequency values in both directions return to values similar to those relevant to the phase before the seismic retrofit intervention (Figure 14). The values of the equivalent viscous damping factor are consistent with the characteristics of the structure.

\section{REFERENCES}

Chopra, A.K. 2007. Dynamics of Structures 3rd ed. Prentice Hall, New Jersey.

Ditommaso, R. \& Ponzo, F.C. (2015). Automatic evaluation of the fundamental frequency variations and related damping factor of reinforced concrete framed structures using the Short Time Impulse Response Function (STIRF). Engineering Structures 82:104-112.

Dolce, M., Nicoletti, M., De Sortis, A., Marchesini, S., Spina, D. \& Talanas, F. 2017. Osservatorio sismico delle strutture: the Italian structural seismic monitoring network. Bull Earthquake Eng 15:621-641.

Iacovino, C., Ditommaso, R., Limongelli, M.P. \& Ponzo, F.C. (2018). The Interpolation Evolution Method for damage localization in structures under seismic excitation. Earthquake Engineering \& Structural Dynamics 47:2117-2136.

INGV, Summary report on the 30 October, 2016 Earthquake in central Italy MW 6.5, 2016.

Maia, N.M.M., Silva, J.M.M., Almas, E.A.M. \& Sampaio, R.P.C. 2003. Damage detection in structures: from mode shape to frequency response function methods. Mechanical Systems and Signal Processing 17:489-498.

Nuove norme tecniche per le costruzioni. D.M. Infrastrutture 17 Gennaio 2018.

Pierdicca, A., Clementi, F., Fortunati, A. \& Lenci, S. 2019. Tracking modal parameters evolution of a school building during retrofitting works. Bulletin of Earthquake Engineering 17:1029-1052.

Sampaio, R.P.C., Maia, N.M.M. \& Silva, J.M.M. 1999. Damage detection using the frequency-response-function curvature method. Journal of Sound and Vibration 226:10291042 .

Thomson, W.T. 1993. Theory of Vibration with Applications, 4th ed. Prentice-Hall, New Jersey. 